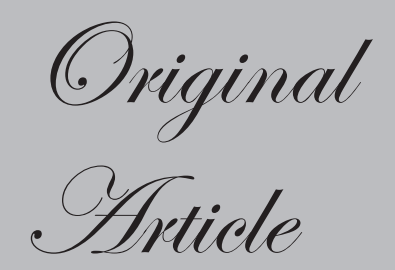

Centre for Liver, Pancreas and Small Bowel Transplantation and ${ }^{2}$ Department of Radiology, 3Biostatistics Department, Apollo Hospitals (Main), Greams Road, Chennai, Tamilnadu, India.

Correspondence: Dr. Dinesh Zirpe Email:drdkzirpe@gmail.com

\section{Determinants of the approach for hepatectomy: outcome of a prospective analytical study}

\author{
DineshZirpe ${ }^{1}$, AzazAhmed ${ }^{1}$, Rochita Venkataramanan ${ }^{2}$, \\ Balasubramaniam Ramakrishnan ${ }^{3}$, Anand Khakhar ${ }^{1}$, \\ Anil Vaidya ${ }^{1}$, Anand Ramamurthy ${ }^{1}$
}

\section{ABSTRACT}

Background: The anterior approach (AA) technique has been advocated recently for right hepatectomy. However, the indications to opt for AA or conventional approach (CA) remain inconsistent.

Objective: To evaluate preoperative factors influencing the approach for hepatectomy.

Methods: A prospective study was performed on 17 patients who underwent hepatic resection from January 2014 to December 2015. All patients were planned to undergo hepatectomy with CA. The decision to adopt an AA was determined by the operating surgeon at the time of laparotomy when mobilization of the tumor before parenchymal transection was considered dangerous or difficult.

Results: Comparing the pre operative characteristics of AA group with $\mathrm{CA}$, there was no significant difference except for the total liver volume (TLV) $(p=0.0001)$, Tumor volume (TV) $(p=0.0001)$, and Largest Tumor Dimension (LTD) $(\mathrm{p}=0.0001)$. Using Receiver Operating Characteristic Curve the volume with optimal sensitivity and specificity which may alter the intra-operative plan from conventional to anterior approach was at $1858 \mathrm{cc}, 1130 \mathrm{cc}$ and $11 \mathrm{~cm}$ for TLV, TV and LTD respectively. Outcome of hepatectomy in both groups were comparable to each other and to the available data.

Conclusion: Of all the analyzed preoperative factors which may affect the approach for hepatectomy TLV, TV and LTD appear to be significant determinant factors.

KEYWORDS: Hepatectomy, Hepatic resection, Liver volume.

\section{Introduction}

Liver resection has evolved over the past few decades, showing improved outcomes anda consistent decrease in perioperative mortality. This has been possible due to advances in imaging, refinements in surgical techniques and devices, along with improved anesthesia support and postoperative management. 
A conventional approach (CA), consisting of the complete mobilization of the liver before parenchymal transection ${ }^{1-4}$, may not be feasible in patients where tumor location, size or infiltration may limit or prohibit access and mobilization before transection. Attempts to mobilize the liver may result in excessive bleeding, iatrogenic tumor rupture or dissemination of cancer cells into the systemic circulation. ${ }^{5}$

In this situation, an anterior approach (AA) has been proposed as a useful alternative. Several prospective and retrospective clinical trials report the feasibility, safety and efficacy of AA. However, how to preoperatively decide to choose the AA remains unclear.

The objective of this study was to evaluate preoperative factors influencing the approach for hepatectomy.

\section{Methods}

This was a prospective observational study on all patients who underwent major right hepatic resection from January 2014 to December 2015. Patient with preoperative evidence of cirrhosis were excluded. Major hepatic resection was defined as resection of three or more liver segments according to the Couinaud nomenclature. 6 All patients underwent a detailed preoperative evaluation including tests of liver function and cardiopulmonary anesthesia evaluation. A 320 slice triphasic multidetector computed tomography (MDCT) of the abdomen was used to determine thelargest tumor dimension (LTD), tumor volume(TV), total liver volume (TLV) and remnant liver volume (RLV).

A conventional approach was the preferred technique. It was upto the operating surgeon to decide to go for an AA at the time of laparotomy, when mobilization of the tumor before parenchymal transection was considered dangerous or difficult.

In $\mathrm{CA}$, hepatic parenchymal transection was performed after complete mobilization of the hepatic lobe and selective ligation and division of the vascular inflow pedicle. In the AA, initial hilar dissection and selective control of the vascular inflow pedicle was similar to the conventional approach. However, mobilization of the tumor and the right lobe of liver was not performed. The plane of parenchymal transection was marked along the ischemic line obtained after clamping or ligating the inflow pedicles. Parenchymal transection was performed using ultrasonic dissector or waterjet depending upon the preference of the operating surgeon. Transection was performed till the anterior surface of the inferior vena cava was reached. Small caval venous branches were individually ligated and the respective hepatic vein was isolated, clamped, divided and sutured outside the liver parenchyma. Once the specimen was completely disconnected from the inferior vena cava, the right hepatic lobe was mobilized from the right abdominal cavity by dividing the ligamentous attachments and was delivered.

Patients were nursed in the intensive care unit during the early postoperative course. Early enteral nutrition was encouraged and progressed as tolerated by patient. Perioperative complications were recorded prospectively using the Clavien-Dindoclassification of surgical complications. ${ }^{7}$ Post-operative mortality was defined as any death occurring within 30 days after surgery.

Research protocol was approved by the institutional review board and all participantsgave written informed consent.

\section{Statistical Analysis}

All the continuous variables were expressed as median (inter quartile range). All the categorical variables were expressed as percentages. Comparison of non-normally distributed continuous variables were done by Mann Whitney $U$ test. Comparison of categorical variables were done using either chi square test or Fisher's exact Test. Receiver Operating Characteristic (ROC) curve was drawn to find out the cut off value. Ap value $<0.05$ was considered statistically significant. Data entry was done in MS Excel spread sheet. Data analysis was done in SPSS. (Version 16.0)

\section{Results}

Seventeen patients underwent major hepatectomy between January 2014 and December 2016. Table 1 shows the distribution of cases as per the diagnosis. Details of the 
Table 1: Distribution of case cohort as per the diagnosis.

\begin{tabular}{l|l} 
Diagnosis & $\mathbf{n}(\mathbf{\%})$ \\
Hepatocellular Carcinoma & $12(70.5)$ \\
\hline Hemangioma & $2(11.7)$ \\
\hline Cholangiocarcinoma & $1(5.8)$ \\
\hline Secondary Metastasis & $2(11.7)$ \\
\hline Total & 17
\end{tabular}

Table 2: Type of hepatectomy.

\begin{tabular}{l|l} 
Type of surgery & $\mathbf{n}(\%)$ \\
Right hepatectomy & $13(76.4)$ \\
\hline $\begin{array}{l}\text { Right hepatectomy and } \\
\text { caudate lobectomy }\end{array}$ & $2(11.7)$ \\
\hline Right trisegmentectomy & $2(11.7)$ \\
\hline Total & 17 \\
\hline Total & 17
\end{tabular}

hepatectomy is shown in Table 2. A comparative study was done between the CA and AA groups. The AA group included 6 patients. The 'hanging' maneuver was used in 2 of these 6 patients to facilitate parenchymal transection. Median size of the tumor was $15 \mathrm{~cm}(12.5-17.5)$ Median TLV was 2605.5cc (2330-2648). Five of the AA group underwent right hepatectomy and one underwent extended right hepatectomy with median operating time of $440 \mathrm{~min}(380-480)$. The median length of hospital stay was 6.5(6-7)days. Median intra-operative blood loss was $550 \mathrm{ml}(500-700)$. Two patient developed a grade II surgical site infection and one required diuretics for high drain output. There was no mortality in these patients with median follow up of 6 months. For all hepatic resections, margins were negative for tumor.

The CA group included 11 patients. Two of them underwent right hepatectomy with caudate lobectomy, one underwent right extended hepatectomy and remaining eight required right hepatectomy. Median total liver volume was $1530 \mathrm{ml}(1410-1675.5)$. Median operating time was $320 \mathrm{~min}(285-525)$. Median intra-operative blood loss was $300 \mathrm{cc}$ (200-500). The median length of hospital stay was 6 days(5-8.5). Mortality was seen in two patients due to post-operative sepsis and multi organ failure $(\mathrm{p}=0.51)$ and one patient required post-operativepercutaneous drainage
Table 3 : Clinicopathological characteristics of patients undergoing hepatectomy.

\begin{tabular}{|c|c|c|c|}
\hline Characteristics & $\begin{array}{l}\text { Anterior } \\
\text { Approach }(n=6)\end{array}$ & $\begin{array}{l}\text { Conventional } \\
\text { approach }(n=11)\end{array}$ & P value \\
\hline $\begin{array}{l}\text { Age (years), } \\
\text { Median (Range) }\end{array}$ & $62(54.5-66.5)$ & $62.5(57-68)$ & 0.660 \\
\hline $\begin{array}{l}\text { Sex } \\
\text { male }\end{array}$ & $5(83.3 \%)$ & $8(72.7 \%)$ & 1.000 \\
\hline Female & $1(16.7 \%)$ & $3(27.3 \%)$ & \\
\hline BMI (kg/m2) & $20.7(20.2-22.7)$ & $22.6(20.2-25.5)$ & 0.076 \\
\hline $\begin{array}{l}\text { Largest tumor } \\
\text { dimension }\end{array}$ & $15(12.5-17.5)$ & $7(5.25-9.25)$ & $0.0001^{*}$ \\
\hline $\begin{array}{l}\text { Total liver } \\
\text { volume }(\mathrm{cc})\end{array}$ & $\begin{array}{l}2605.5 \\
(2330-2648) \\
\end{array}$ & $\begin{array}{l}1530 \\
(1410-1675.5) \\
\end{array}$ & $0.0001^{*}$ \\
\hline $\begin{array}{l}\text { Remnant liver } \\
\text { volume (cc) }\end{array}$ & $1342(800-1506)$ & $780(685-930)$ & 0.078 \\
\hline $\begin{array}{l}\text { Total tumor } \\
\text { volume }\end{array}$ & $1883(1610-3472)$ & $\begin{array}{l}253.5 \\
(113.7-490.3) \\
\end{array}$ & $0.0001^{*}$ \\
\hline ASA 2 & $3(50 \%)$ & $9(81.8 \%)$ & 0.280 \\
\hline ASA 3 & $3(50 \%)$ & $2(18.2 \%)$ & \\
\hline $\begin{array}{l}\text { Operative } \\
\text { time(minute) }\end{array}$ & $440(380-480)$ & $320(285-525)$ & 0.404 \\
\hline $\begin{array}{l}\text { Intraoperative } \\
\text { transfusion }\end{array}$ & $4(66.7 \%)$ & $2(18.2 \%)$ & 0.109 \\
\hline Blood loss $(\mathrm{ml})$ & $550(500-700)$ & $300(200-500)$ & 0.122 \\
\hline Complication & $3(50 \%)$ & $8(72.7 \%)$ & 0.600 \\
\hline $\begin{array}{l}\text { Hospital stay } \\
\text { (days) }\end{array}$ & $6.5(6-7)$ & $6(5-8.5)$ & 0.961 \\
\hline $\begin{array}{l}\text { Hospital } \\
\text { Mortality }\end{array}$ & $0(0 \%)$ & $2(18.1 \%)$ & 0.51 \\
\hline
\end{tabular}

for an abdominal collection. Five patients in this group suffered minor complication (grade I or II) and were managed conservatively. No other major complication was noted in this group.The extent of hepatic resection was comparable between the two groups of patients (Table 3). Duration of the operation was comparable in the two groups $(\mathrm{p}$ value $=0.404)$. Patients in the AA group had marginally increased blood loss and increase in transfusion requirement which was not statistically significant $(p$ value $=0.122)$. There was no iatrogenic tumor rupture during mobilization but one patient from AAgroup required intraoperative intercostal tube drainage as diaphragm was excised partially along with tumor. Operative morbidity was comparable in both groups. 
Comparing the pre-operative characteristics of AA group with CA, there was no significant difference except for the TLV $(p=0.0001), T V(p=0.0001)$ and largest tumor dimension $(\mathrm{p}=0.0001)$.

Based on our data, using the Receiver Operating Characteristic Curve (Figure 1) the volume with optimal sensitivity and specificity which may alter the intraoperative plan from conventional to anterior approach was a tumor volume of $1130 \mathrm{cc}$ and a total liver volume of 1858. Largest tumor dimension of $11 \mathrm{~cm}$ or more was associated increase possibility of conversion to AA, intraoperatively.

\section{Discussion}

Conventional approach for hepatectomy requires complete mobilization of the liver before parenchymal transection. This was considered a standard procedure and was widely used for major right hepatic resection worldwide. Subsequently,the anterior approach was introduced which entailed transection of the liver parenchyma before mobilization of the right liver. ${ }^{8,9}$ Numerous previous studies have reported several important prognostic factors capable of predicting the outcome of patients undergoing liver resection. ${ }^{10,11}$ However, the present study analyzed whether preoperative factors could predict the optimal approach for hepatectomy. The respective volumes of hepatic tumors and RLV of patients requiring hepatectomy were measured using CT volumetry. In a recent study, the average accuracy, sensitivity, specificity and percent volume error of CT estimated hepatic volume was $98.4 \%$, $91.1 \%, 99.1 \%$, and $7.2 \%$ respectively. ${ }^{12}$

AA has the additional advantage of minimizing tumor cell dissemination which could greatly reduce the chance of postoperative HCC recurrence, as this is a prominent indication (31.8\%) for hepatectomy in our experience. However, the anterior approach can be technically challenging due to congestion and bleeding from the collaterals from the diaphragmatic attachments once the hepatic vein is divided. Bleeding can also be encountered at a deeper plane of parenchymal transection from the right or the middle hepatic vein or the IVC. The outcome of hepatectomy in both groups was found to be comparable to each other and to the available data.

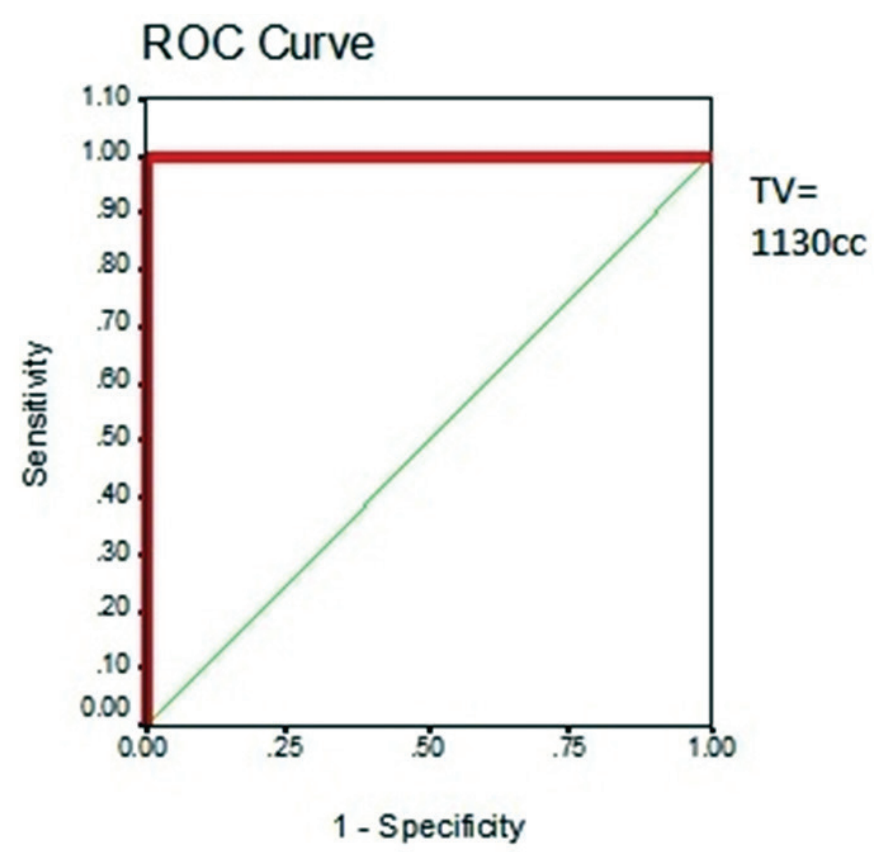

Figure 1: ROC curve for TV.

The purpose of the study was to find out whether patients requiring ananterior approach could be predicted preoperatively. Apart from LTD, TV and TLV, other analyzed preoperative variables did not show any statistical significance. The limitations of the study were its comparatively small sample size and heterogeneity. There are no previous studies that analyzed total liver volume as determinant factor for hepatectomy approach. Further studies including patient selection, feasibility of liver resection and outcomes based on approach may be required.

In conclusion, LTD, TV and TLV as determined by preoperative $\mathrm{CT}$ volumetry appear to beuseful in the selection of approach for parenchymal transection in major liver resections. Further prospective studies are required to validate these values.

\section{References}

1. Starzl TE, Bell RH, Beart RW, Putnam CW. Hepatic trisegmentectomy and other liver resections. SurgGynecolObstet 1975; 141:429-437.

2. Fortner JG, Kim DK, Maclean BJ. Major hepatic resection for neoplasia: personal experience in 108 patients. Ann Surg 1978; 188: 363-371. 
3. Schwartz SI. Right hepatic lobectomy. Am J Surg 1984; 148:668-673.

4. Blumgart LH. Liver resection: liver and biliary tumours. In: Blumgart LH ed. Surgery of the Liver and Biliary Tract, 2d ed. London Churchill Livingstone; 1994:1495-1537

5. Ozawa K. Hepatic function and liver resection. J GastroenterolHepatol 1990; 5:296-309.

6. Couinaud C. Le Foie. Etudes AnatomiquesetChirurgicales. Paris: Masson; 1957.

7. Dindo D., Demartines N., Clavien P.A.; Ann Surg. 2004; 244: 931-937

8. Belghiti J, Guevara OA, Noun R, et al. Liver hanging maneuver: asafe approach to right hepatectomy without liver mobilization. J AmColl Surg. 2001;193:109-111.
9. Lai EC, Fan ST, Lo CM, et al. Anterior approach for difficult majorrighthepatectomy. World J Surg. 1996;20:314-317.

10. Lee WC, Jeng LB, Chen MF. Estimation of prognosis after hepatectomyfor hepatocellular carcinoma. Br J Surg. 2002;89:311-316.

11. Yeh $\mathrm{CN}$, Chen MF, Lee WC, et al. Prognostic factors of hepaticresection for hepatocellular carcinoma with cirrhosis: univariateandmultivariate analysis. J SurgOncol. 2002;81:195-202.

12. Suzuki K, Kohlbrenner R, Epstein ML, Obajuluwa AM, Xu J, Hori M. Computer-aided measurement of liver volumes in CT by means of geodesic active contour segmentation coupled with level-set algorithms. Medical physics. 2010 May 1;37(5):2159-66. 